\title{
Nanoporous aluminum oxide membranes for biomedical micro hydraulic devices
}

\author{
Giedrius Janusas ${ }^{1}$, Asta Guobiene ${ }^{2}$, Arvydas Palevicius ${ }^{3}$, Lukas Ramalis ${ }^{4}$ \\ ${ }^{1,3}$ Faculty of Mechanical Engineering, Kaunas University of Technology, Kaunas, Lithuania \\ ${ }^{2}$ Institute of Materials Science, Kaunas University of Technology, Kaunas, Lithuania \\ ${ }^{4}$ Faculty of Mathematics and Natural Sciences, Kaunas University of Technology, Kaunas, Lithuania \\ ${ }^{1}$ Corresponding author \\ E-mail:19iedrius.janusas@ktu.lt,2ªsta.guobiene@ktu.lt,3arvydas.palevicius@ktu.lt, \\ ${ }^{4}$ lukas.ramalis@ktu.edu
}

Received 8 November 2017; accepted 22 November 2017

DOI https://doi.org/10.21595/vp.2017.19448

Check for updates

Abstract. The main aim of this paper is to create nanoporouse aluminium oxide membrane which could be used as vibroactive nanofilter in biomedical micro hydraulic devices. This research paper covers the experimental setup of nanoporouse aluminium oxide membrane fabrication and the investigations of its chemical and surface properties. A custom-made anodization experimental setup was used to form membrane with hexagonal pores of $70 \mathrm{~nm}$ diameter and $110 \mathrm{~nm}$ interpore distance.

Keywords: micro hydraulic devices, nanoporous membranes, aluminium oxide, biomedical devices, anodization.

\section{Introduction}

In case of formation of microstructures suitable for practical applications in biomedicine one needs to have their external dimensions at least of the order of millimeters and also to have the possibility to control their internal structure (of the order of micrometers or nanometers) easily. There are a lot of investigations in the field of periodic microsystems and their application in biomedical research [1], real-time monitoring of optical constants, physical, chemical and biological processes [2-3], biologically attractive two-dimensional and three-dimensional micro formations (micro structures) [4,5], direct laser recording, based on multi photon photo polymerisation [6-8] or 3D printing [9]. They enable forming of micro formations (micro structures) of the necessary inner geometry but just in small volume and very slowly. Other technologies such as solvent casting and particulate leaching [10], phase separation [11] or gas foaming [12] enable forming micro formations (micro structures) quite fast and in large volumes, but control of internal geometry of micro formations (micro structures) formed by these methods is very poor. Control methods of micro fluids by applying acoustic manipulation are known in the world too. For this purpose standing and travelling waves are excited in micro channels [13]. The generated walls of micro hydro dynamical systems are excited by vibration methods which ensure more effective flow of micro fluids [14]. Thin PZT films are integrated into micro dynamical systems thus ensuring their more effective functionality [15]. Therefore, in this paper it is proposed to create nanoporouse aluminium oxide membrane, with predefined geometrical dimension, which could be used as vibro active nano filter in biomedical micro hydraulic devices.

\section{Experimental setup}

Nanoporous aluminium oxide membranes were formed using two step anodization. Before anodization process, the aluminium sheet was ultrasonically cleaned in acetone for 5 minutes at room temperature and in phosphoric acid for 3 minutes. The first step of anodization in oxalic acid takes 1 hour. During it non ordered pores of aluminium oxide were formed. This initial layer of pores was removed using chromium acid for 30 minutes at $55^{\circ} \mathrm{C}$ temperature. The second step of anodization in oxalic acid takes 24 hours under a voltage of $60 \mathrm{~V}$. The unreacted aluminium was removed using chloride acid for 10 minutes at $55{ }^{\circ} \mathrm{C}$ temperature. The diameter of pores and 
distance between them depends from electrolyte used in anodization process [16]. From theory oxalic acid is used to create pores of $40-100 \mathrm{~nm}$ diameter with the inter pore distance of 80-200 nm [16].

Equipment used in anodization process is presented in Fig. 1. It consists from DC power supply (1), ammeter (2), holder (5) and bath with electrolyte (6). During all process electrolyte was cooled using water (4) and stirred by electromagnetic mixer (3).

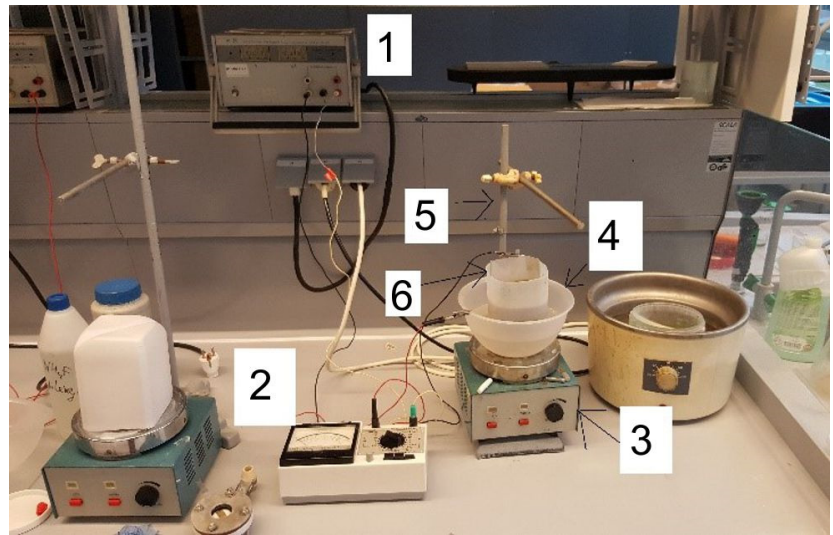

Fig. 1. Experimental setup of anodization process

Fourier transform infrared spectroscopy (FTIR, SPECTRUM GX 2000 RAMAN, PerkinElmer, Waltham, Massachusetts, USA) was used for the investigation of changes in chemical composition of aluminium sheet after anodization process. The diapason of FTIR spectrum was 4,000-400 $\mathrm{cm}^{-1}$ with resolution of $1 \mathrm{~cm}^{-1}$. The investigation of surface morphology was done using the atomic force microscope NT-206 with resolution of 1-20 nm, which depends on the sharpness of the tip.

\section{Results}

The photo and surface morphology of nanoporous aluminium oxide membrane formed using two step anodization (electrolyte - oxalic acid) are presented in Fig. 2. Diameter of the membrane is $30 \mathrm{~mm}$ (Fig. 2(a)).

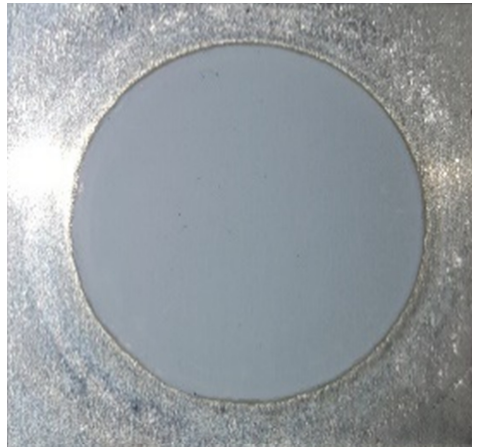

a)

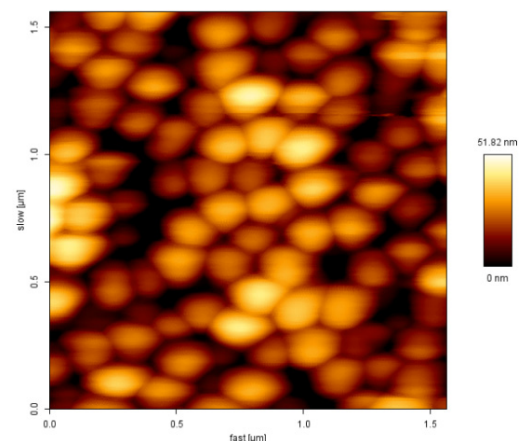

b)

Fig. 2. Photo a) and surface morphology b) of nanoporous aluminium oxide membrane

Surface morphology of the formed elements was analysed using atomic force microscopy. 2D view of the arbitrary selected area of the size $1.5 \times 1.5 \mu \mathrm{m}$ is presented in Fig. 2(b).

For the detailed analysis and measurement of pores diameters and interpore distances $3 \mathrm{D}$ view 
(Fig. 3) and topography (Fig. 4) of the membrane were created. According to the theory, hexagon structures were obtained during anodization process.

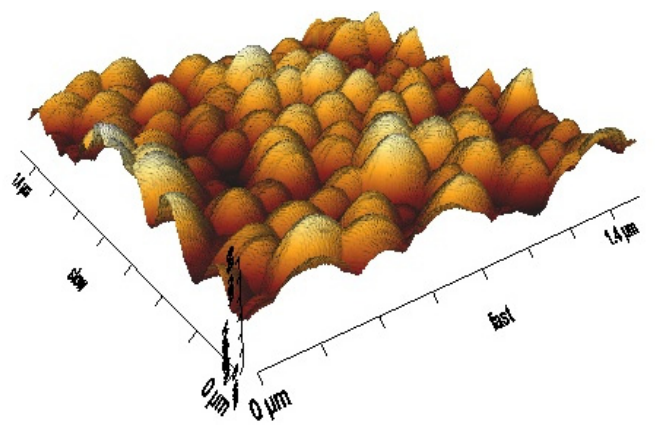

Fig. 3. 3D view of nanoporous aluminium oxide membrane

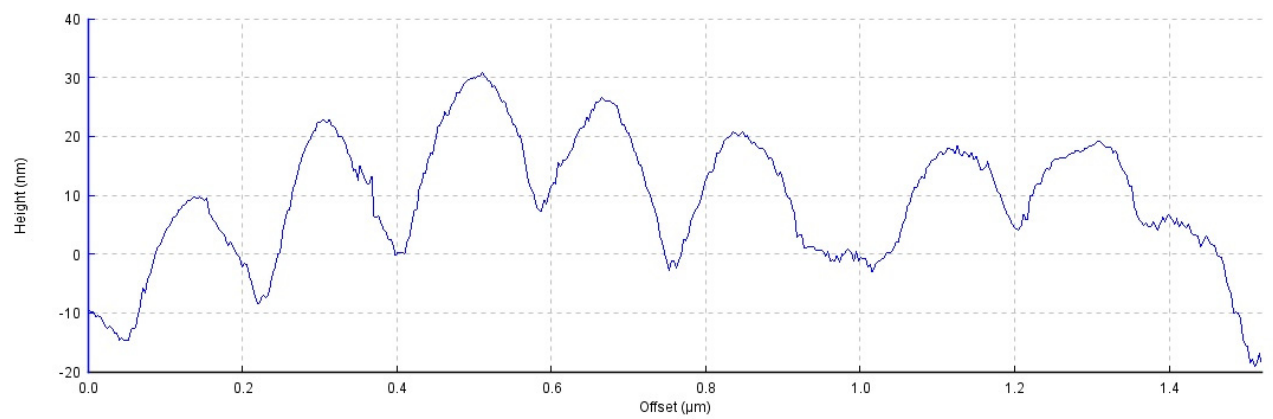

Fig. 4. Profile of nanoporous aluminium oxide membrane

Comparison of theoretical and experimental results of pore diameters and interpore distances are presented in Table 1. It is obvious that experimental results correspond to the theoretical values. The experimentally measured diameter of pores varies from 50 to $90 \mathrm{~nm}$, whereas the interpore distance is more stable i.e. variation does not exceed $10 \%$.

Table 1. Comparison of theoretical and experimental values

\begin{tabular}{|c|c|c|c|}
\hline & Pore diameter, $\mathrm{nm}$ & Interpore distance, $\mathrm{nm}$ & Voltage, $\mathrm{V}$ \\
\hline Experimental value & $70 \pm 20$ & $110 \pm 10$ & 60 \\
\hline Theoretical value & $40-100$ & $80-200$ & $30-80$ \\
\hline
\end{tabular}

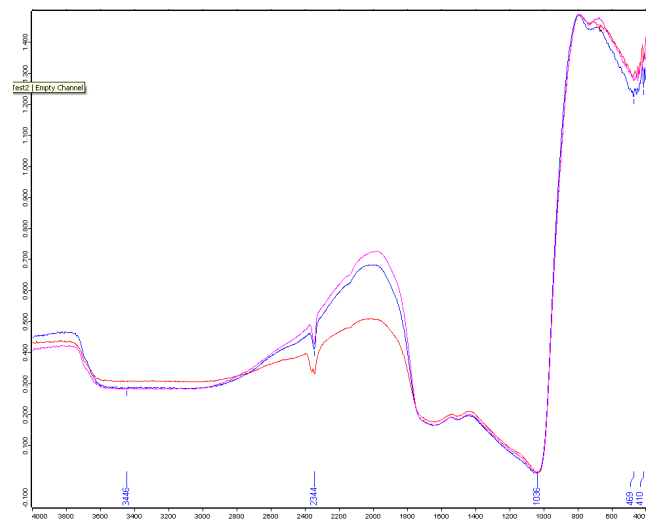

Fig. 5. FTIR transmittance spectra (a.u.) of three nanoporous aluminium oxide membranes for wavenumber of $4000-400 \mathrm{~cm}^{-1}$ 
Fourier transform infrared spectroscopy analysis of the nanoporous aluminium oxide membranes was done. FTIR transmittance spectrum at $4000-400 \mathrm{~cm}^{-1}$ of the $\mathrm{Al}_{2} \mathrm{O}_{3}$ membrane is presented in Fig. 5. There was no significant difference in three analysed specimens. In the FTIR spectra strong and weak transmittance peaks were observed at $3446 \mathrm{~cm}^{-1}, 2344 \mathrm{~cm}^{-1}, 1036 \mathrm{~cm}^{-1}$, $469 \mathrm{~cm}^{-1}$ and $410 \mathrm{~cm}^{-1}$. The entire array of these peaks corresponds to the FTIR transmittance spectra of $\mathrm{Al}_{2} \mathrm{O}_{3}$ [17], what confirms that nanoporous aluminium oxide membranes were formed.

These nanoporous aluminum oxide membranes (diameter $-30 \mathrm{~mm}$, thickness $-0.2 \mathrm{~mm}$ ) fixed on top of the piezoelectric ring (PZT-5H, outer diameter $-30 \mathrm{~mm}$, thickness $-3 \mathrm{~mm}$, high $-3 \mathrm{~mm}$ ) could be used for cells filtration. Response of the membrane to electrical excitation of $1 \mathrm{~V}$ at frequency of $1300 \mathrm{~Hz}$ is presented in Fig. 6. Vibration of the membrane allows to control the geometry of nanoporous and to reduce the friction which may damage cells during the filtration process.

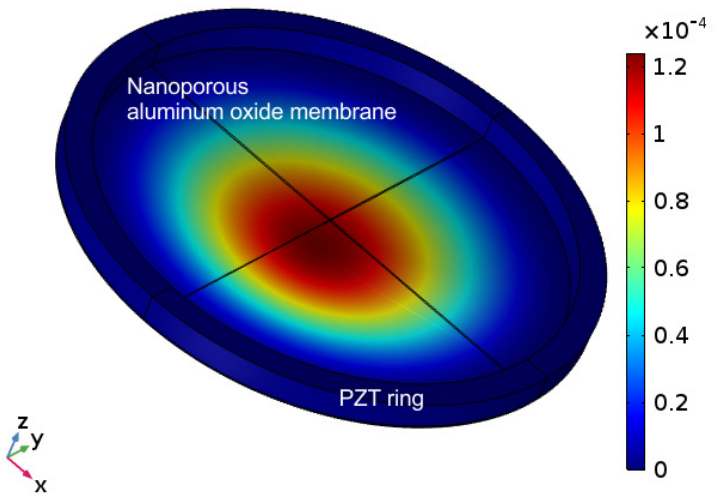

Fig. 6. Vibration of nanoporous aluminum oxide membrane

\section{Conclusions}

Nanoporous aluminium oxide membranes with hexagonal pores of $70 \mathrm{~nm}$ diameter and $110 \mathrm{~nm}$ interpore distance were formed using custom-made anodization experimental setup. Periodical excitation of the membrane allows to control geometry of nanoporous and to reduce friction which may damage cell membrane. Therefore, these membranes excited at $1.3 \mathrm{kHz}$ frequency could be used as vibroactive nanofilters in biomedical micro hydraulic devices.

\section{Acknowledgement}

This research was funded by a Grant S-MIP-17-102 from the Research Council of Lithuania.

\section{References}

[1] Ostasevicius V., Janusas G., Palevicius A., Gaidys R., Jurenas V. Biomechanical Microsystems Design, Processing and Applications. Springer, Switzerland, 2017.

[2] Juknius T., Ružauskasm, Tamulevičiust, Šiugždinienė R., Juknienė I., Vasiliauskas A., Jurkeviciute A., Tamulevičius S. Antimicrobial properties of diamond-like carbon/silver nanocomposite thin films deposited on textiles: towards smart bandages. Materials, Vol. 9, Issue 5, 2016, p. 1-15.

[3] Bružauskaitė I., Bironaitė D., Bagdonas E., Skeberdis V. A., Denkovskij J., Tamulevičius T., Uvarovas V., Bernotienė E. Relevance of HCN2-expressing human mesenchymal stem cells for the generation of biological pacemakers. Stem Cell Research and Therapy, Vol. 7, 2016, p. 1-15.

[4] Danilevicius P., Rekstyte S., Balciunas E., Kraniauskas A. Micro-structured polymer scaffolds fabricated by direct laser writing for tissue engineering. Journal of Biomedical Optics, Vol. 17, Issue 8, 2012 , p. 81405. 
[5] Stankevičius E., Gedvilas M., Voisiat B., Malinauskas M., Račiukaitis G. Fabrication of periodic micro-structures by holographic lithography. Lithuanian Journal of Physics, Vol. 53, Issue 4, 2013, p. $227-237$.

[6] Sun H. B., Kawata S. Two-photon photopolymerization and 3D lithographic microfabrication. Advances in Polymer Science, Vol. 170, 2004, p. 169-273.

[7] Wu S., Serbin J., Gu M. Two-photon polymerisation for three-dimensional micro-fabrication. Journal of Photochemistry and Photobiology A, Vol. 181, 2006, p. 1-11.

[8] Malinauskas M., Gilbergs H., Žukauskas A., Purlys V., Paipulas D., Gadonas R. A femtosecond laser-induced two-photon photopolymerization technique for structuring microlenses. Journal of Optics, Vol. 12, Issue 3, 2010, p. 1-8.

[9] Silva D. N., De Oliveira M. G., Meurer E., Meurer M. I., Da Silva J. V., Santa Bárbara A. Dimensional error in selective laser sintering and 3Dprinting of models for craniomaxillary anatomy reconstruction. Journal of Cranio-Maxillofacial Surgery, Vol. 36, 2008, p. 443-449.

[10] Sin D., Miao X., Liu G., Wei F., Chadwick G., Yan C., Friis T. Polyurethane (PU) scaffolds prepared by solvent casting/particulate leaching (SCPL) combined with centrifugation. Materials Science and Engineering C, Vol. 30, 2010, p. 78-85.

[11] Liu X., Ma P. X. Phase separation, pore structure, and properties of nanofibrous gelatin scaffolds. Biomaterials, Vol. 30, 2009, p. 4094-4103.

[12] Salerno A., Oliviero M., Di Maio E., Iannace S., Netti P. Design of porous polymeric scaffolds by gas foaming of heterogeneous blends. Journal of Materials Science: Materials in Medicine, Vol. 20, 2009, p. 2043-2051.

[13] Kozuka T., Yasui K. Acoustic manipulation in a microchannel. Proceedings of 20th International Congress on Acoustic, Sydney, Australia, 2010.

[14] Ogawa J., Kanno I., Kotera H., Wasa K., Suzuki T. Development of liquid pumping devices using vibrating microchannel walls. Sensors and Actuators A, Vol. 152, 2009, p. 211-218.

[15] Cazorla P. H., Fuchs O., Coschet M., Maubert S., Le Rhun G., Foullet Y., Defay E. Integration of PZT thin films on a microfluidic complex system. IEEE International Ultrasonics Symposium Proceedings, 2014, p. 491-494.

[16] Mankotia D., Singh P. S., Kaur M. Review of anodic porous alumina membrane development. SSRG International Journal of Humanities and Social Science, 2015, p. 48-53.

[17] Prashanth P. A., Raveendra R. S., Hari Krishna R., Ananda S., Bhagya N. P., Nagabhushana B. M., Lingaraju K., Raja Naika H. Synthesis, characterizations, antibacterial and photoluminescence studies of solution combustion-derived $\alpha-\mathrm{A} 12 \mathrm{O} 3$ nanoparticles. Journal of Asian Ceramic Societies, Vol. 3, Issue 3, 2015, p. 345-351. 